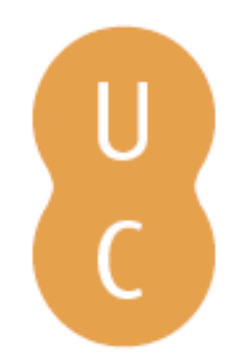

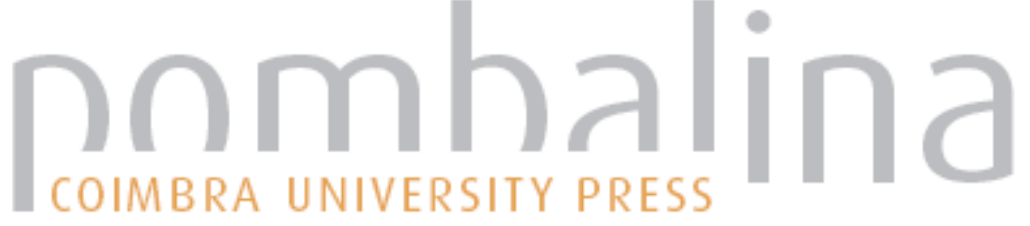

\section{A União Europeia e os 'Estados falhados': uma narrativa securitizadora no alinhamento internacional?}

\author{
Autor(es): $\quad$ Brandão, Ana Paula \\ Publicado por: Imprensa da Universidade de Coimbra \\ URL \\ persistente: URI:http://hdl.handle.net/10316.2/47427 \\ DOI: $\quad$ DOl:https://doi.org/10.14195/978-989-26-1524-0_3 \\ Accessed : $\quad$ 26-Apr-2023 15:00:41
}

A navegação consulta e descarregamento dos títulos inseridos nas Bibliotecas Digitais UC Digitalis, UC Pombalina e UC Impactum, pressupõem a aceitação plena e sem reservas dos Termos e Condições de Uso destas Bibliotecas Digitais, disponíveis em https://digitalis.uc.pt/pt-pt/termos.

Conforme exposto nos referidos Termos e Condições de Uso, o descarregamento de títulos de acesso restrito requer uma licença válida de autorização devendo o utilizador aceder ao(s) documento(s) a partir de um endereço de IP da instituição detentora da supramencionada licença.

Ao utilizador é apenas permitido o descarregamento para uso pessoal, pelo que o emprego do(s) título(s) descarregado(s) para outro fim, designadamente comercial, carece de autorização do respetivo autor ou editor da obra.

Na medida em que todas as obras da UC Digitalis se encontram protegidas pelo Código do Direito de Autor e Direitos Conexos e demais legislação aplicável, toda a cópia, parcial ou total, deste documento, nos casos em que é legalmente admitida, deverá conter ou fazer-se acompanhar por este aviso.

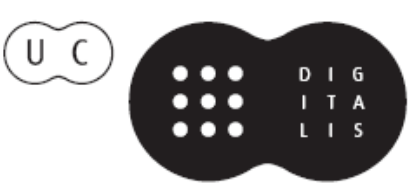


JOSÉ MANUEL PUREZA JOSÉ JUSTE RUIZ (COORDS.)
IMPRENSA DA

UNIVERSIDADE

DE COIMBRA

COIMBRA

UNIVERSITY

PRESS
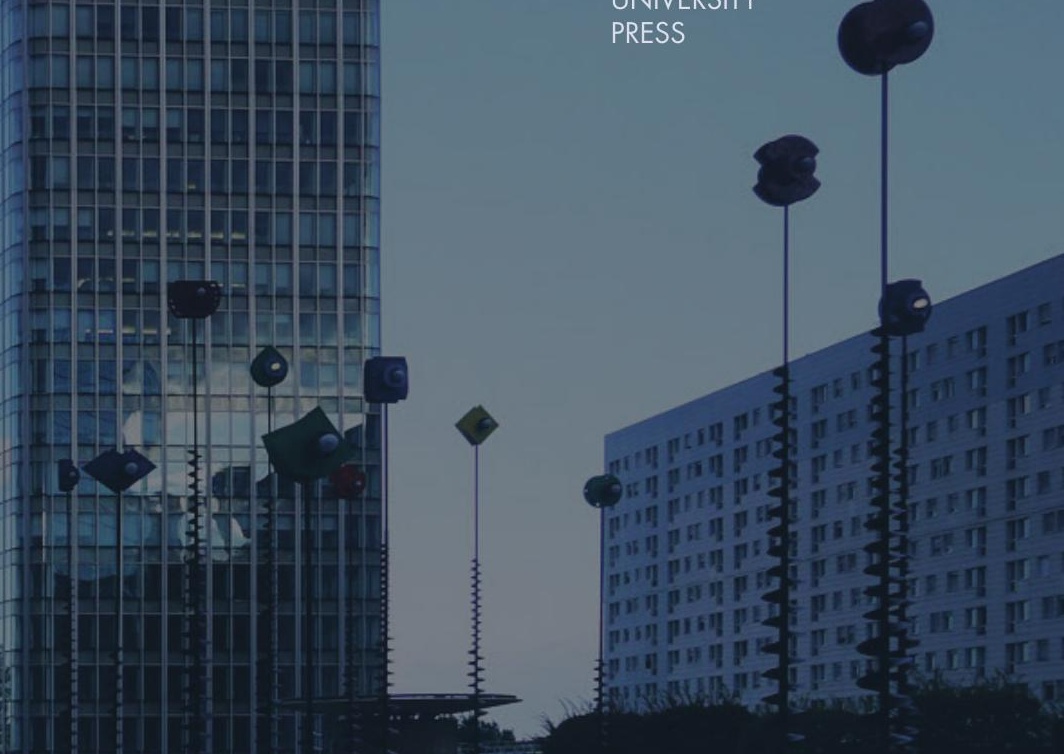

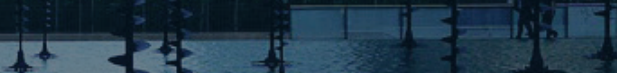

OS ESTADOS

EA ORDEM

INTERNACIONAL

CONTEMPORANEA

ATAS DO V ENCONTRO LUSO-ESPANHOL DE Professores de Direito internacional e RELAÇÕES INTERNACIONAIS 


\section{A UNIÃO EUROPEIA E OS 'ESTADOS FALHADOS': UMA NARRATIVA SECURITIZADORA NO A L I N H A M E N T O I NTERNACIONAL?}

\section{Ana Paula Brandão}

A narrativa internacional do pós-Guerra Fria, amplificada pela resposta aos ataques de 11 de setembro de 2001 e subsequentes, evidencia uma tendência securitizadora associada a dinâmicas co-constitutivas da designada abordagem holística (comprebensive approach): alargamento (segurança multissectorial) e aprofundamento (segurança multinível), nexos securitários (interno-externo, segurança-desenvolvimento ${ }^{2}$, pobreza-conflito, civil-militar, público-privado), internalização da segurança externa e externalização da segurança interna. Um dos efeitos da comprehensive approach traduz-se na clivagem Norte-Sul reconstruida em termos de segurança/ insegurança: a 'periferia de instabilidade e insegurança' (pobreza, conflito, fragilização estatal, nexo interameaças) que, segundo o discurso, ameaça o 'centro de estabilidade e segurança'. Distanciada a probabilidade de ameaças clássicas, leia-se a agressão por parte de um Estado vizinho, as lideranças ocidentais reconstroem o discurso securitário assente na proximidade globalizada de uma

\footnotetext{
1 A primeira versão do texto foi publicada em State Building and Fragility Monitor 5/2014.

${ }^{2}$ Vide Klingebiel, 2006; Chadler, 2007.
} 
periferia insegura e imprevisível. A preocupação centra-se na externalização dos efeitos da instabilidade e conflitualidade internas no limite traduzida na 'proximidade' da insegurança geograficamente distante e/ou na ameaça de uma periferia desgovernada ${ }^{3}$, terreno fértil para ameaças transnacionais ${ }^{4}$.

A actorness da União Europeia começou por expressar-se no plano económico e só mais tarde no plano securitário. Volvidas décadas de atuação nas áreas do comércio, do desenvolvimento e da ajuda humanitária, a explicitação do ator de segurança deu-se com a entrada em vigor do Tratado da União Europeia que consagrou a cooperação no domínio quer da segurança externa (Política Externa e de Segurança Comum) quer da segurança interna (cooperação policial e judiciária em matéria penal). Ainda que obedecendo a uma matriz fragmentada, a coordenação entre os primeiro e segundo pilares (interpilarização) começou por emergir associada ao nexo segurança/desenvolvimento, no domínio específico da prevenção de conflitos. No pós 11 de Setembro, a muldimensionalidade da ameaça terrorista justificou o recurso a instrumentos dos três pilares (transpilarização), reforçando a necessidade do já há muito reclamado fim da estrutura fragmentada, tal como viria a acontecer, pelo menos formalmente, com a revisão de Lisboa.

3 A título exemplificativo, de referir o projeto do Pentágono relativo às 'áreas desgovernadas' e respetivo relatório final (Lamb 2008).

4 "Every threat to international security today enlarges the risk of other threats. (...) The ability of non-State actors to traffic in nuclear material and technology is aided by ineffective State control of borders and transit through weak States." (United Nations 2004, 19) International terrorist groups prey on weak States for sanctuary. (...) Poverty, infectious disease, environmental degradation and war feed one another in a deadly cycle." (id. 20). "Civil war, disease and poverty increase the likelihood of State collapse and facilitate the spread of organized crime, thus also increasing the risk of terrorism and proliferation due to weak States and weak collective capacity to exercise the rule of law." (id., 21) "In what ways does fragility matter? Fragile states matter because they are home to a growing share of the world's poor. They are also more susceptible to instability, with potential regional and global consequences. Crisis and conflict prevention are more cost-efficient than engaging after the damage has been done." (OECD 2012,35) 
Esta evolução tem sido acompanhada por uma narrativa de atorness "forçosamente global" (Conselho Europeu 2003, 1), entendida em termos quer de alcance geográfico quer de abordagem política, ambos justificados pelo contexto da globalização, pela oportunidade e responsabilidade acrescida da UE nesse contexto e pela necessidade de fazer face às vulnerabilidades, riscos e ameaças que o mesmo potencia: "Numa era de globalização, as ameaças longínquas podem ser tão preocupantes como as que estão próximas de nós" (Conselho Europeu 2003, 6). De notar que também concorrem para a abordagem holística outros fatores, menos declarados, relacionados com dinâmicas históricas e institucionais internas, designadamente a possibilidade de a UE utilizar know-how, instrumentos e recursos de áreas políticas historicamente consolidadas em prol do domínio da segurança, bem como a influência e o interesse da Comissão que tem vantagem acumulada nessas áreas e no entendimento amplo e 'civilista' da segurança. A narrativa da abordagem holística 5 e dos nexos securitários, designadamente os nexos segurança/desenvolvimento e segurança interna/externa, tem sido extensiva ao fenómeno da fragilidade estatal.

A UE comunga do entendimento internacional do fenómeno em termos de défice de governação ${ }^{6}$ (Hout 2010): "O conceito de fragilidade refere-se a estruturas débeis ou em desagregação e a situações em que o contrato social é rompido devido à incapacidade ou à falta de vontade do Estado de assumir as suas funções de base, cumprir as suas obrigações e responsabilidades no que diz respeito à prestação de serviços, gestão de recursos, Estado de

\footnotetext{
5 Também designada de 'global', 'integral' ou 'interdisciplinar'.

${ }^{6}$ De acordo com a Comissão, os elementos da fragilidade podem abarcar as nove áreas dos "perfis da governação", (European Commission 2008): 1. governação política/democrática; 2. governação política/Estado de Direito; 3. controlo da corrupção; 4. eficácia governamental; 5. Governação económica; 6. Segurança interna e externa; 7. governação social; 8. contexto internacional e regional; 9. qualidade da parceria [SEC (2009) 58 final, p. 6].
} 
Direito, acesso equitativo ao poder, segurança da população e proteção e promoção dos direitos e liberdades dos cidadãos" (Comissão Europeia 2007, 5). Subscrevendo os compromissos internacionais relativos aos Estados frágeis e matérias relacionadas ${ }^{7}$, a UE partilha da 'whole-of-government approach'8 (European Commission 2008, 1), para a qual é considerada particularmente vocacionada, porque dotada de "uma aptidão única para combinar, de uma forma coerente, políticas e instrumentos que vão desde a diplomacia, a segurança e a defesa até ao financiamento, ao comércio, ao desenvolvimento e à justiça"9 (Conselho Europeu, 2013, 3). Assim, uma panóplia de organismos e instrumentos ${ }^{10}$ são utilizados na prevenção e resposta à fragilidade estatal, tendo sido selecionados, durante a presidência portuguesa, seis estados piloto ${ }^{11}$, entre os quais Guiné-Bissau e Timor-Leste, para testar a abordagem holística definida em 2007 (Council of the EU 2007).

Apesar das potencialidades da União, que a distinguem da maior parte das agências e organizações internacionais de cooperação (European University Institute 2009, 124), a sua atuação em prol da

7 DAC guidelines on conflict, peace and development cooperation (1997); DAC guidelines on helping prevention violent conflict (2001); DAC guidelines on SSR and governance (2005); Declaração de Paris sobre a Eficácia da Ajuda (2005); DAC guidelines on whole of government approach to fragile states (2006); DAC Handbook on Security System Reform (2007); DAC Principles for good international engagement in fragile states and situations (2007); Agenda de Accra para a Ação (2008).

8 Adaptada para 'whole-of-EU approach' (European Commission 2008, 3).

9 "Já existe um quadro estratégico para fazer face às diversas dimensões da fragilidade. O Consenso Europeu sobre o Desenvolvimento proporciona orientações para uma resposta abrangente à problemática da fragilidade. Insere-se num quadro mais vasto de acções externas que deve ser activado na sua totalidade para que a União possa reagir às situações de fragilidade de forma atempada e coerente. Este quadro inclui a Estratégia Europeia de Segurança, o programa da UE para a prevenção dos conflitos violentos, a Política Europeia de Vizinhança, o quadro estratégico para a Interligação entre Ajuda de Emergência, Reabilitação e Desenvolvimento, o Consenso em matéria de Ajuda Humanitária e a abordagem da UE no âmbito da governação e do desenvolvimento." (Comissão Europeia 2007, 5)

${ }^{10}$ Para uma descrição detalhada, vide Parlamento Europeu 2013, 16-21.

11 Burundi, Guiné-Bissau, Haiti, Iémen, Serra Leoa, Timor-Leste. 
'resiliência' estatal tem evidenciado fragilidades, designadamente: défice de coordenação interna (interinstitucional, interpolíticas e interníveis) e externa, e ineficácia dos sistemas de alerta precoce (European Parliament 2013); abordagem tecnocrática incidindo sobre a reforma das instituições públicas em detrimento da ação sobre as causas profundas da fragilidade (Hout 2010; Castillejo 2011); lentidão, inflexibilidade e inadequação dos instrumentos europeus (Castillejo 2011); falta de clarificação operacional face a objetivos ambiciosos (Briscoe 2008). O facto de se aguardar ainda pela finalização do plano de ação em matéria de segurança, fragilidade e desenvolvimento, solicitado pelo Conselho em 2007, é sintomático das debilidades europeias.

Para lá do racional humanitário e económico, no pós-11 de Setembro intensificou-se o racional securitário da narrativa europeia na justificativa de resposta às situações de fragilidade. Ao imperativo humanitário de luta contra a pobreza global e de defesa dos direitos fundamentais das pessoas pobres e vulneráveis, que "são as mais afectadas em situações de fragilidade" (Comissão Europeia 2007), amplifica-se a preocupação com a externalização do espiral de "ameaças dinâmicas" (Conselho Europeu 2003, 7) conexas propiciado pela falta de controlo interno dos Estados frágeis. O fracasso ${ }^{12}$ dos Estados é considerado "um fenómeno alarmante que mina a governação à escala global e contribui para a instabilidade regional" (Conselho Europeu 2003, 4), pelo que é incluído na lista das principais ameaças ao espaço europeu, e ainda percecionado como um fator potenciador de outras ameaças, tais como o terrorismo ${ }^{13}$, a criminalidade orga-

\footnotetext{
12 Embora predomine o uso do termo 'fragilidade' (dos Estados), os documentos oficiais da UE também utilizam 'colapso', 'fracasso' e 'degenerescência'.

$13 \mathrm{Na}$ última comunicação relativa à prevenção da radicalização, a Comissão recomenda que a UE e os seus Estados-Membros promovam " iniciativas em países terceiros, com especial ênfase nos países frágeis ou afetados por conflitos, países em transição ou países caracterizados por uma governação deficiente" (Comissão europeia 2013,12 ), e compromete-se "[I]ntegrar estratégias de prevenção da radi-
} 
nizada (Conselho Europeu 2003 e 2010), "a imigração ilegal e, mais recentemente, a pirataria" (Conselho Europeu 2008, 1).

Ainda que as prioridades da agenda europeia tenham sido alteradas em contexto de crise, o efeito da dinâmica securitizadora persiste. Nas palavras do Secretário-Geral adjunto para as Questões Interinstitucionais do Serviço Europeu para a Ação Externa, a segurança "é um investimento para a estabilidade" e a sua inclusão "como um objetivo no quadro pós-2015 é um elemento essencial para o desenvolvimento" (apud Koczij 2013, 8 e 9). Esta inflexão tem contribuído para um maior envolvimento da UE no Estados frágeis e nos Estados (regiões e setores) "órfãos de ajuda”, mas sem favorecer o tratamento das causas profundas da fragilidade estatal e obedecendo a um racional securitário de clivagem que contraria a natureza normativa do ator europeu.

\section{Referências}

Briscoe, Ivan. 2008. "The EU Response to Fragile States”. European Security Review (42). Brussels: ISIS Europe. Disponível em: http://www.isis-europe.eu/sites/ default/files/programmes-downloads/2008_artrel_227_esr42-eufragilestates.pdf.

Castillejo, Clare 2011. "Improving European Policy towards Fragile States". Policy Brief (95). Madrid: FRIDE. Disponível em:

http://www.fride.org/download/PB_95_Improving_European_policy_towards_fragile_ states.pdf.

Chadler, David. 2007. "The Security-Development Nexus and the Rise of 'Anti-foreign Policy”. Journal of International Relations and Development 10: 362-386.

calização e do extremismo violento em instrumentos tradicionais de cooperação para o desenvolvimento, especialmente em Estados frágeis vulneráveis ao extremismo violento" (id. 13). Na comunicação conjunta com a Alta Representante, em texto destacado: "Terrorist organisations will strive to exploit post-conflict or fragile states. In particular, poorly governed areas can prove to be a breeding ground for terrorist recruitment. For example, the activities of Al-Shabaab - which is formally aligned with Al Qaeda - have destabilised Somalia, and severely hindered regional development. Terrorist organisations can act to transmit the terrorist threat directly back into the EU." (European Commission e High Representative 2013, 9). 
European Parliament, Directorate-General for External Policies. 2013. EU Development Cooperation in Fragile States. Brussels. Disponível em: http://www.europarl.europa. eu/RegData/etudes/etudes/join/2013/433724/EXPO-DEVE_ET(2013)433724_EN.pdf.

European University Institute. 2009. European Report on Development 2009: Overcoming Fragility in Africa: Forging a New European Approach. Disponível em: http:// ec.europa.eu/europeaid/what/development-policies/research-development/ documents/erd_report_2009_en.pdf.

Hout, Wil. 2010. "Between Development and Security: The European Union, Governance and Fragile States". Third World Quarterly 31(1): 141-157.

Koczij, David (rel.). 2013. Post-2015-Objective Peace: Sustained Solutions to Fragility, Conflict and Violence: Challenges and Opportunities: Panel Debate at the EU Development Days (EDDs) co-organised by Friends of Europe as part of the Development Policy Forum (DPF). Brussels: Friends of Europe. Disponível em: http://www.friendsofeurope.org.

Klingebiel, S (ed.). 2006. New Interfaces between Security and Development, D.I.E. Studies 13. Bonn: Deutsches Institut für EntwicklungspolitiK.

Lamb, Robert D. 2008. Ungoverned Areas and Threats from Safe Havens: Final Report of the Ungoverned Areas Project Prepared for the Office of the Under Secretary of Defense for Policy. Office of the Under Secretary of Defense for Policy. Disponível em: http://www.cissm.umd.edu/papers/files/ugash_report_final.pdf.

OECD. 2012. Fragile States 2013: Resource Flows and Trends in a Shifting World. Disponível em: http://www.oecd.org/dac/incaf/FragileStates2013.pdf

United Nations, Secretary-General. 2004. The Secretary-General's High-level Panel Report on Threats, Challenges and Change, A More Secure World: Our Shared Responsibility (A/59/565). Disponível em: http://www.unrol.org/doc.aspx?n=gaA.59.565_En.pdf. 